\title{
Produtividade, qualidade de tubérculos e incidência de doenças em batata, influenciados pela aplicação foliar de silício
}

\author{
Rogério Peres Soratto(1), Adalton Mazetti Fernandes ${ }^{(1)}$, Carlos Alexandre Costa Crusciol(1) \\ e Genivaldo David de Souza-Schlick ${ }^{(1)}$
}

(1)Universidade Estadual Paulista, Faculdade de Ciências Agronômicas, Campus de Botucatu, Caixa Postal 237, CEP 18603-970 Botucatu, SP.
E-mail: soratto@fca.unesp.br, adalton@fca.unesp.br, crusciol@fca.unesp.br, genivald@fca.unesp.br

Resumo - O objetivo deste trabalho foi avaliar o efeito da aplicação de silício por via foliar, na forma de ácido silícico estabilizado, sobre a incidência de doenças, produtividade e qualidade de batata. Foram realizados três experimentos: um com a cultivar Agata e outro com a Atlantic, em Botucatu, SP; e um com a cultivar Agata, em Itaí, SP. Utilizou-se delineamento de blocos ao acaso, com oito repetições. Os tratamentos consistiram de: testemunha (sem aplicação de $\mathrm{Si}$ ) e aplicação de Si via foliar, na dose $2 \mathrm{~L} \mathrm{ha}^{-1}$, de produto comercial com $0,8 \%$ de Si solúvel como concentrado estabilizado de ácido silícico. A dose de Si foi parcelada em quatro aplicações durante o ciclo da cultura. A aplicação de Si reduz a severidade da requeima e a incidência de canela-preta, além de aumentar a produtividade e o teor de matéria seca dos tubérculos. O fornecimento de Si via foliar aumenta a produtividade de tubérculos, independentemente de seus efeitos sobre a incidência de doenças.

Termos para indexação: Pectobacterium, Phytophthora infestans, Solanum tuberosum, ácido silícico estabilizado, adubação foliar, requeima.

\section{Yield, tuber quality, and disease incidence on potato crop as affected by silicon leaf application}

\begin{abstract}
The objective of this work was to evaluate the effects of silicon leaf application, in the form of stabilized silicic acid, on the disease incidence, yield, and quality of potato. Three experiments were carried out: one with the cultivar Agata and another with Atlantic, in Botucatu, SP, Brazil; and one with the cultivar Agata, in Itaí, SP. A randomized complete block design was used, with eight replicates. The treatments consisted of: a control (without $\mathrm{Si}$ ) and $\mathrm{Si}$ foliar spraying at $2 \mathrm{~L} \mathrm{ha}^{-1}$ of a commercial product containing $0.8 \%$ of soluble $\mathrm{Si}$ as concentrated, stabilized silicic acid. The silicon dose was split in four applications during the crop cycle. Silicon application reduces the severity of late blight and the incidence of blackleg, besides increasing tuber yield and tuber dry matter content. Leaf-supplied silicon increases potato tuber yield, regardless of its effect on disease incidence.

Index terms: Pectobacterium, Phytophthora infestans, Solanum tuberosum, stabilized silicic acid, leaf spray, late blight.
\end{abstract}

\section{Introdução}

A cultura da batata (Solanum tuberosum L.) apresenta grande importância como fonte de alimento para as populações humanas, em termos de quantidade produzida e consumida (Fernandes et al., 2010b). No entanto, a cultura é muito suscetível a diversas doenças que, a depender das condições climáticas e de manejo, podem reduzir drasticamente a produtividade (Duarte et al., 2008).

Embora o silício ( $\mathrm{Si}$ ) não seja considerado fisiologicamente essencial para o crescimento das plantas, e ainda seja pouco conhecido e utilizado na agricultura brasileira, vários estudos têm mostrado os efeitos benéficos da sua aplicação em espécies acumuladoras como arroz, cana-de-açúcar, cevada, milho, sorgo e trigo (Ma et al., 2001; Gong et al., 2005; Hattori et al., 2005; Sousa et al., 2010; Gong \& Chen, 2012). Também plantas dicotiledôneas, consideradas não acumuladoras, como tomate (Lana et al., 2003), pepino (Liang et al., 2005), café (Reis et al., 2008), grão-de-bico (Gunes et al., 2007), girassol (Gunes et al., 2008), morango (Carré-Missio et al., 2010), tremoço (Abdalla, 2011) e batata (Pulz et al., 2008; Crusciol et al., 2009) têm respondido positivamente a aplicação de Si.

A ação benéfica do $\mathrm{Si}$ tem sido associada ao aumento da capacidade fotossintética das plantas, 
desenvolvimento de plantas mais eretas, redução da transpiração, aumento da resistência mecânica das células, maior resistência das plantas a insetos e doenças, diminuição do efeito tóxico do $\mathrm{Mn}$, Fe e outros metais pesados, e aumento da absorção e metabolismo de elementos, tais como o fósforo (Lana et al., 2003; Gong et al., 2005; Hattori et al., 2005; Carré-Missio et al., 2010; Sousa et al., 2010).

$\mathrm{Na}$ maioria das vezes, o Si é fornecido ao solo por meio do uso de escórias de siderurgia, na forma de silicatos de $\mathrm{Ca}$ e $\mathrm{Mg}$, que são fontes de baixíssima solubilidade em água (Sousa et al., 2010). No entanto, a absorção do Si é um processo ativo, com gasto energético mesmo quando as raízes estão em presença de altas concentrações do elemento (Malavolta, 2006), pois as plantas absorvem $\mathrm{Si}$ exclusivamente como ácido monossilícico, também chamado de ácido ortossilícico $\left[\mathrm{Si}(\mathrm{OH})_{4}\right]$ (Elawad \& Green Junior, 1979). Essa forma de Si é encontrada na água doce e salgada, a baixas concentrações $\left(<10^{-4} \mathrm{~mol} \mathrm{~L}^{-1}\right)$, e se gelatiniza formando sílica gel, quando em elevadas concentrações ou baixo pH (Calomme et al., 2000).

$\mathrm{O}$ fornecimento de $\mathrm{Si}$ mediante pulverização foliar tem sido considerado alternativa viável para fornecimento às plantas, pois supre a necessidade de Si e estimula seus efeitos benéficos (Wang \& Galleta, 1998; Buck et al., 2008; Reis et al., 2008; Carré-Missio et al., 2010; Sousa et al., 2010). A aplicação de Si via foliar também auxilia no controle de doenças. Guével et al. (2007) relataram que aplicações semanais de Si via foliar proporcionaram redução da severidade do oídio em trigo. Carré-Missío et al. (2012) verificaram que a aplicação de Si via foliar reduziu significativamente o índice de esporulação, o número total de pústulas e a severidade da ferrugem (Hemileia vastatrix Berk \& $\mathrm{Br}$ ) em folhas de cafeeiro. Gonçalves (2009) observou aumento linear da produtividade total, comercial e da classe extra de tubérculos de batata, em consequência da aplicação de doses crescentes de silicato de potássio via foliar; porém, nesse trabalho foram realizadas 14 aplicações durante o ciclo da cultura, o que deixou dúvidas sobre se o efeito foi do Si ou do K aplicado.

Fontes que apresentam $\mathrm{Si}$ na forma de ácido silícico estabilizado, que formam principalmente ácido ortossilícico quando diluídas, podem ser uma alternativa viável para aumentar a absorção do elemento pelas plantas e resultar em efeitos benéficos, mesmo com poucas aplicações durante o ciclo. Contudo, são praticamente inexistentes na literatura trabalhos científicos relacionados ao fornecimento de $\mathrm{Si}$ via foliar, que tenham utilizado como fonte o ácido silícico estabilizado.

O objetivo deste trabalho foi avaliar o efeito da aplicação de $\mathrm{Si}$, por via foliar, na forma de ácido silícico estabilizado, sobre a incidência de doenças, produtividade e qualidade de tubérculos, na cultura da batata.

\section{Material e Métodos}

Foram realizados três experimentos de aplicacação de Si via foliar. Em Botucatu, SP, foram conduzidos os experimentos 1 e 3, na Fazenda Experimental Lageado $\left(22^{\circ} 51^{\prime} \mathrm{S}, 48^{\circ} 26^{\prime} \mathrm{W}\right.$, à altitude de $\left.740 \mathrm{~m}\right)$; e o experimento 2 foi conduzido no Município de Itaí, SP, em campo de produção comercial de batata $\left(23^{\circ} 28^{\prime} \mathrm{S}\right.$, $49^{\circ} 08^{\prime} \mathrm{W}$, e à altitude de $670 \mathrm{~m}$ ).

O preparo do solo das áreas experimentais foi feito de forma convencional, com arações e gradagens. Os experimentos 1, 2 e 3 foram instalados em 24/03/2009, 09/04/2009, e 06/05/2010, respectivamente, com tubérculos-semente das cultivares Agata (experimentos 1 e 2) e Atlantic (experimento 3). Nos experimentos 1 e 2, utilizaram-se tubérculossemente tipo III (diâmetro entre $30-40 \mathrm{~mm}$ ), no espaçamento de $0,80 \mathrm{~m}$ entre linhas e $0,35 \mathrm{~m}$ entre os tubérculos-semente, enquanto no experimento 3 foram utilizados tubérculos-semente tipo IV (diâmetro entre 23-30 mm), no espaçamento de $0,80 \mathrm{~m}$ entre fileiras e $0,20 \mathrm{~m}$ entre os tubérculos-semente.

Nos experimentos 1 e 3, foi utilizada adubação de $1.500 \mathrm{~kg} \mathrm{ha}^{-1}$ da fórmula N-P-K 8-28-16, nos sulcos de plantio, e de $200 \mathrm{~kg} \mathrm{ha}^{-1}$ da fórmula N-P-K 20-00-20, em cobertura, aos 35 dias após o plantio (DAP). A adubação no experimento 2 consistiu da aplicação de $2.169 \mathrm{~kg} \mathrm{ha}^{-1}$ da fórmula N-P-K 4-30-10 + 0,2\% $\mathrm{B}+0,5 \% \mathrm{Zn}$, no sulco de plantio, e de $215 \mathrm{~kg} \mathrm{ha}^{-1} \mathrm{da}$ fórmula N-P-K 20-00-20, em cobertura, aos 30 DAP. Em todos os experimentos, a operação de amontoa foi realizada imediatamente após a adubação de cobertura.

Empregou-se o delineamento experimental de blocos ao acaso, com oito repetições. Os tratamentos foram constituídos por: testemunha (sem aplicação de $\mathrm{Si}$ ) e aplicação de $\mathrm{Si}$ via foliar, com $2 \mathrm{~L} \mathrm{ha}^{-1}$ de produto comercial com $0,8 \%$ de Si solúvel, como concentrado estabilizado de ácido silícico, que forma os ácidos ortossilícico $\left[\mathrm{Si}(\mathrm{OH})_{4}\right]$ e dissilícico quando diluídos em 
água (Bioquick Tecnologia Importação e Exportação de Produtos Agropecuários Ltda., Cotia, SP). A dose de Si foi parcelada em quatro aplicações durante o ciclo da cultura. As aplicações de Si foram realizadas aos: 26, 35, 50 e 65 DAP, no experimento 1; aos 32, 39, 53 e 67 DAP, no experimento 2; e aos 20,34, 48 e 62 DAP, no experimento 3. Para isso, utilizou-se um pulverizador manual pressurizado com $\mathrm{CO}_{2}$, com volume de calda de $250 \mathrm{~L} \mathrm{ha}^{-1}$ na $1^{\mathrm{a}}$ aplicação, $350 \mathrm{~L} \mathrm{ha}^{-1}$ nas $2^{\mathrm{a}}$ e $3^{\mathrm{a}}$ aplicações, e $500 \mathrm{~L} \mathrm{ha}^{-1}$ na $4^{\mathrm{a}}$ aplicação. Cada unidade experimental foi constituída por seis fileiras de $6 \mathrm{~m}$ de comprimento.

A irrigação das áreas experimentais foi realizada por sistema de aspersão do tipo convencional, de acordo com as recomendações técnicas para a cultura na região, durante todo o ciclo da cultura. Foram realizadas pulverizações para o controle de pragas e doenças, com defensivos químicos registrados para a cultura, sempre que necessário.

As avaliações quanto à requeima [Phytophthora infestans (Mont.) de Bary] foram feitas nas folhas superiores e inferiores de oito plantas das linhas centrais de cada parcela, tendo-se empregado a escala diagramática adaptada de Azevedo (1998). A incidência de canela-preta (Pectobacterium spp.) foi obtida pela contagem do número de plantas atacadas, nas duas linhas centrais de cada unidade experimental. Nos experimentos 1 e 2, as avaliações foram realizadas aos 67 e 81 dias após a emergência (DAE). No experimento 3 , as avaliações foram realizadas aos 62 e 76 DAE.

Nos experimentos 1 ('Agata') e 3 ('Atlantic'), a colheita foi realizada após a secagem natural das hastes, tendo-se coletado os tubérculos de 15 plantas das linhas centrais de cada unidade experimental, respectivamente aos 120 e aos 116 DAP. No experimento 2 ('Agata'), foi realizada a dessecação da parte aérea das plantas aos 94 DAP, com o herbicida diquat ( $330 \mathrm{~g}$ do i.a. ha ${ }^{-1}$ ). Aos 17 dias após a dessecação, os tubérculos de 12 plantas das linhas centrais de cada unidade experimental foram colhidos.

Em todos os experimentos, foram determinadas as seguintes variáveis: número total de tubérculos e número de tubérculos comercializáveis por planta; massa de matéria fresca média dos tubérculos e dos tubérculos comercializáveis; produtividade total; produtividade comercial (tubérculos com diâmetro $>23 \mathrm{~mm}$ ); e teor de matéria seca nos tubérculos.
Os resultados foram submetidos à análise de variância, e as médias dos tratamentos foram comparadas pelo teste $\mathrm{t}(\mathrm{DMS})$, a $5 \%$ de probabilidade.

\section{Resultados e Discussão}

No experimento 2, não foram observados sintomas expressivos de requeima e canela-preta nas plantas de batata; no entanto, no experimento 1, a requeima alcançou elevados níveis de severidade (Figura 1 A e C). Verificou-se que a severidade da requeima foi menor no tratamento que recebeu $\mathrm{Si}$ via foliar. $\mathrm{Na}$ avaliação realizada aos $81 \mathrm{DAE}$, com a aplicação de $\mathrm{Si}$, a área foliar lesionada pela requeima foi em média 35,4\% menor, nas folhas superiores, e $24,7 \%$ menor, nas inferiores, o que confirma os relatos de Epstein \& Bloom (2006), Guével et al. (2007), Reis et al. (2008) e Carré-Missio et al. (2012) de que o Si auxilia no controle de doenças. Duarte et al. (2008) não observaram diferença significativa quanto à severidade da requeima na cultura da batata, entre tratamentos com aplicação de silicato de potássio via foliar e testemunha, sem aplicação. No entanto, o silicato de potássio não apresenta Si na forma de ácido silícico estabilizado.

No experimento 3, na última avaliação realizada aos 76 DAE, constatou-se que a aplicação de Si reduziu em 44,2 e 35,7\%, em comparação à testemunha, a severidade da requeima nas folhas superiores e inferiores, respectivamente (Figura $1 \mathrm{~B}$ e D). De acordo com Epstein \& Bloom (2006), o Si auxilia o controle alternativo de doenças por meio de dois mecanismos, o físico e o bioquímico. O mecanismo físico compreende uma barreira física formada pela polimerização do Si na superfície foliar, que impede a penetração e o desenvolvimento do patógeno; ocorre também a deposição dentro da folha, que impede a germinação e penetração do patógeno (Rodrigues \& Datnoff, 2005). O mecanismo bioquímico ainda não foi elucidado; porém, acredita-se que a absorção de Si favoreça a formação de fitoalexinas que acumulam-se nos sítios de infecção, junto com o Si (Rodrigues et al., 2004; Rodrigues \& Datnoff, 2005).

A incidência de canela-preta também foi influenciada pelos tratamentos, em ambas as épocas de avaliação no experimento 1 e na última avaliação no experimento 3 , em que a aplicação de Si proporcionou menor número de plantas doentes (Figura 2). Nas últimas avaliações, a incidência de canela-preta no tratamento com 


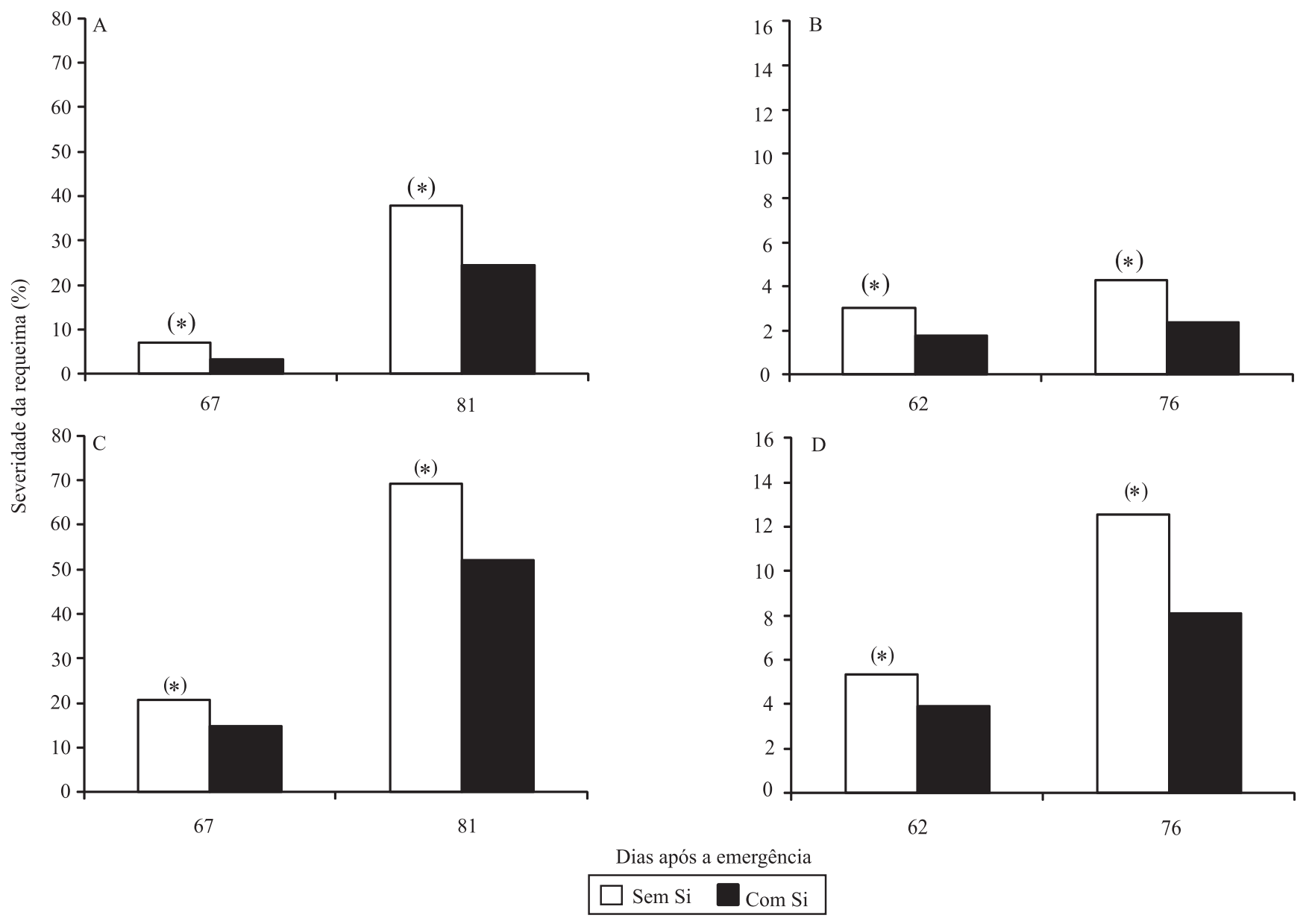

Figura 1. Severidade da requeima, expressa em percentagem da área foliar lesionada, nas folhas superiores (A, B) e inferiores (C, D) da cultura da batata, em função da aplicação de Si via foliar, nos experimentos 1 (A, C) e 3 (B, D). *Significativo pelo teste t, a $5 \%$ de probabilidade, dentro de cada época de avaliação.
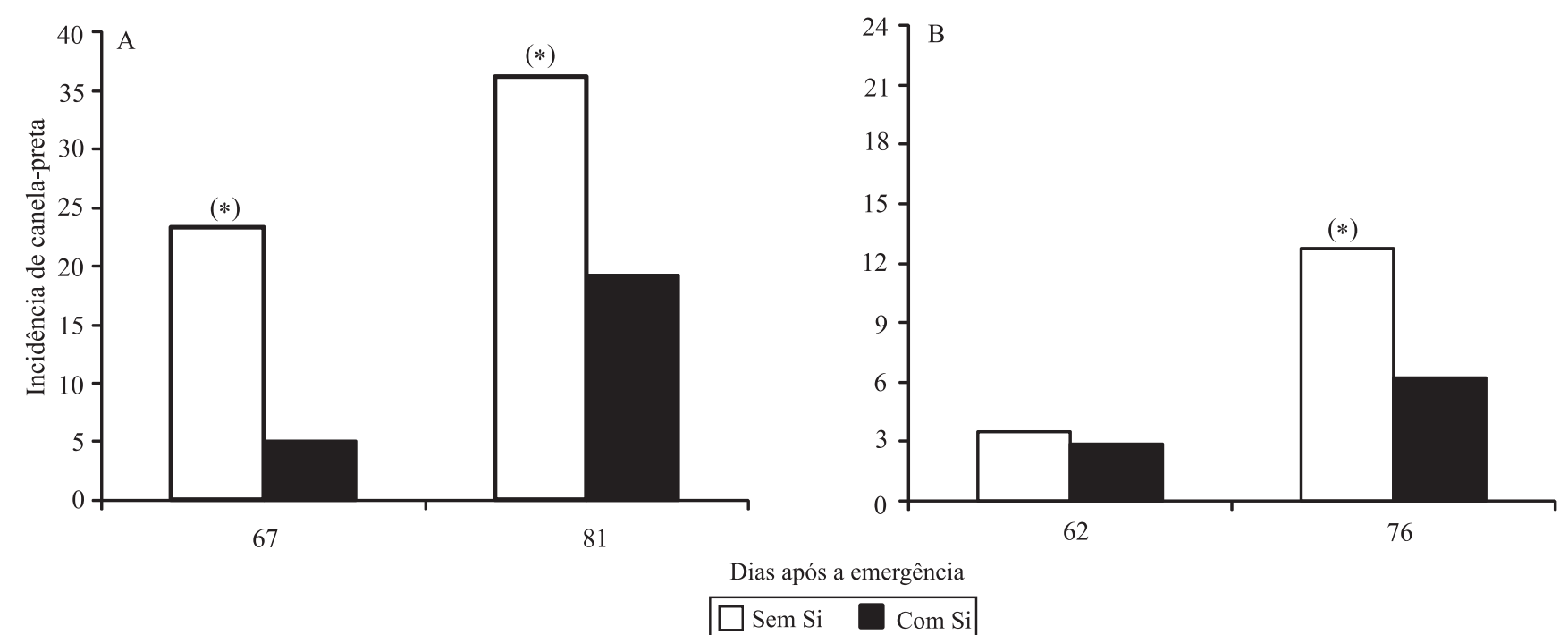

Figura 2. Incidência de canela-preta nas plantas de batata, em função da aplicação de Si via foliar, nos experimentos 1 (A) e 3 (B). *Significativo pelo teste t, a 5\% de probabilidade, dentro de cada época de avaliação. 
aplicação de Si foi 47 e $51 \%$ menor que no tratamento testemunha, nos experimentos 1 e 2, respectivamente (Figura 2 A e B). Segundo Pulz et al. (2008), um dos benefícios da aplicação de Si à cultura da batata é proporcionar maior resistência ao acamamento, e diminuir o contato das hastes com o solo. Segundo Gonçalves (2009), o Si proporciona folhas mais eretas, o que também pode reduzir a incidência de doenças causadas por fitopatógenos do solo, como a canela-preta (Rodrigues et al., 2007).

A aplicação de $\mathrm{Si}$ aumentou o número total de tubérculos somente no experimento 3 (Tabela 1). Já o número de tubérculos comercializáveis foi influenciado pela aplicação de $\mathrm{Si}$ nos experimentos 1 e 3, com maior número nos tratamentos que receberam Si. No experimento 1, a massa de matéria fresca média de tubérculos totais e comercializáveis foi maior no tratamento com $\mathrm{Si}$, enquanto no experimento 3 ocorreu o inverso (Tabela 1). A menor massa média de tubérculos no experimento 3 pode ser atribuída ao maior número de tubérculos por planta observado no tratamento com Si. A maior quantidade de drenos proporciona maior partição dos fotoassimilados entre os tubérculos, característica que pode estar relacionada à cultivar ou às condições de cultivo (Fernandes et al., 2010b). Contudo, no experimento 1 , verificou-se que a aplicação de Si teve influência na massa de matéria

Tabela 1. Número de tubérculos totais e comercializáveis por planta e massa de matéria fresca (MF) média de tubérculos de batata em consequência da aplicação de $\mathrm{Si}$, via foliar, em três experimentos.

\begin{tabular}{|c|c|c|c|}
\hline Tratamentos & Experimento 1 & Experimento 2 & Experimento 3 \\
\hline & \multicolumn{3}{|c|}{ Número total de tubérculos por planta } \\
\hline Sem Si & 8,9 & 18,3 & $4,6^{*}$ \\
\hline Com Si & 9,9 & 19,5 & 5,4 \\
\hline \multirow[t]{2}{*}{$\mathrm{CV}(\%)$} & 9,7 & 9,5 & 6,6 \\
\hline & \multicolumn{3}{|c|}{ Número de tubérculos comercializáveis por planta ${ }^{(1)}$} \\
\hline Sem Si & $7,9 *$ & 16,5 & $4,6^{*}$ \\
\hline Com Si & 8,9 & 17,9 & 5,4 \\
\hline \multirow[t]{2}{*}{$\mathrm{CV}(\%)$} & 8,0 & 8,3 & 6,2 \\
\hline & \multicolumn{3}{|c|}{ Massa de MF média de tubérculos (g por tubérculo) } \\
\hline Sem Si & $45,8^{*}$ & 86,0 & $119,4^{*}$ \\
\hline Com Si & 58,6 & 91,7 & 107,9 \\
\hline \multirow[t]{2}{*}{$\mathrm{CV}(\%)$} & 15,7 & 8,2 & 8,8 \\
\hline & \multicolumn{3}{|c|}{ Massa de MF média de tubérculos comercializáveis ( $\mathrm{g}$ por tubérculo } \\
\hline Sem Si & $50,9 *$ & 95,2 & $119,7^{*}$ \\
\hline Com Si & 63,8 & 99,1 & 107,9 \\
\hline $\mathrm{CV}(\%)$ & 14,7 & 9,2 & 8,5 \\
\hline
\end{tabular}

fresca e não no número de tubérculos por planta. Resultados semelhantes foram obtidos por Pulz et al. (2008), com a aplicação de silicato de $\mathrm{Ca}$ e $\mathrm{Mg}$, via solo, à cultura da batata 'Bintje'.

Quanto à produtividade de tubérculos, verificou-se que a aplicação de $\mathrm{Si}$ via foliar proporcionou maior produtividade total e comercial de tubérculos, nos experimentos 1 e 2 (Tabela 2). Gonçalves (2009), além de observar folhas mais eretas das plantas de batata 'Atlantic', com a aplicação de crescentes doses de silicato de potássio via foliar, obteve também aumento linear da produtividade total, comercial e da classe extra de tubérculos. Embora o Si tenha promovido incremento na produtividade total e comercial de tubérculos do experimento 1 , a produtividade desse ensaio foi baixa, em razão da elevada incidência de requeima e canela-preta (Figuras 1 e 2; Tabela 2).

$\mathrm{O}$ teor de matéria seca (MS) nos tubérculos foi influenciado pela aplicação de Si via foliar apenas nos experimentos 1 e 3 (Tabela 2). No experimento 1, a aplicação de Si reduziu o teor de MS nos tubérculos, provavelmente em razão do elevado incremento em sua produtividade, o que teria causado um efeito de diluição. No experimento 3, observou-se efeito contrário, ou seja, a aplicação de Si não proporcionou incrementos à produtividade de tubérculos, mas aumentou seu teor de MS (Tabelas 1 e 2). Deve-se destacar que a cultivar Atlantic normalmente apresenta maior teor de MS, característica importante para a utilização na

Tabela 2. Produtividade total e comercial e teor de matéria seca de tubérculos de batata em consequência da aplicação de $\mathrm{Si}$, via foliar, em três experimentos.

\begin{tabular}{|c|c|c|c|}
\hline Tratamentos & Experimento 1 & Experimento 2 & Experimento 3 \\
\hline & \multicolumn{3}{|c|}{ Produtividade total de tubérculos $\left(\mathrm{kg} \mathrm{ha}^{-1}\right)$} \\
\hline Sem Si & $14.748 *$ & $55.098^{*}$ & 33.748 \\
\hline Com Si & 20.590 & 62.930 & 33.790 \\
\hline \multirow[t]{2}{*}{$\mathrm{CV}(\%)$} & 14,8 & 7,0 & 5,1 \\
\hline & \multicolumn{3}{|c|}{ Produtividade de tubérculos comercializáveis $\left(\mathrm{kg} \mathrm{ha}^{-1}\right)^{(1)}$} \\
\hline Sem Si & $14.499 *$ & $54.768 *$ & 33.748 \\
\hline Com Si & 20.369 & 62.627 & 33.790 \\
\hline \multirow[t]{2}{*}{$\mathrm{CV}(\%)$} & 18,0 & 6,1 & 5,1 \\
\hline & \multicolumn{3}{|c|}{ Teor de matéria seca nos tubérculos $(\%)^{(2)}$} \\
\hline Sem Si & $15,2 *$ & 14,0 & $20,5^{*}$ \\
\hline Com Si & 14,4 & 13,9 & 21,8 \\
\hline CV (\%) & 4,0 & 4,6 & 4,6 \\
\hline \multicolumn{4}{|c|}{$\begin{array}{l}{ }^{(1)} \text { Classificação segundo o diâmetro transversal dos tubérculo } \\
\text { (comercial, }>23 \mathrm{~mm} \text { ). }{ }^{(2)} \text { Teor de matéria seca, determinada com bas } \\
\text { em amostras proporcionais entre as classes de tamanho de tubérculos } \\
\text { *Significativo pelo teste t, a } 5 \% \text { de probabilidade. }\end{array}$} \\
\hline
\end{tabular}


forma de chips, ou seja, frita em fatias (Fernades et al., 2010a). Crusciol et al. (2009) observaram que a maior disponibilidade de Si no solo, após a aplicação de silicato de $\mathrm{Ca}$ e $\mathrm{Mg}$, foi benéfica à cultura da batata, já que, além da massa média dos tubérculos, ela aumentou seu teor de MS, independentemente da condição de disponibilidade hídrica. Os benefícios à produtividade e à qualidade obtidos resultaram do maior enchimento dos tubérculos, provavelmente em consequência da maior produção de fotoassimilados e pelas alterações na partição destes. Gong et al. (2005) e Hattori et al. (2005) verificaram que o fornecimento de Si promove maior fotossíntese e acúmulo de matéria seca da parte aérea, em plantas de trigo e sorgo, respectivamente.

A aplicação de $\mathrm{Si}$ interfere significativamente na incidência de doenças e, mesmo na ausência de doenças, pode aumentar a produtividade da batata, por interferir em processos fisiológicos da planta, conforme mostrado por outros trabalhos (Wang \& Galleta, 1998; Lana et al., 2003; Gunes et al., 2007; Crusciol et al., 2009; Sousa et al., 2010; Abdalla, 2011; Gong \& Chen, 2012).

\section{Conclusões}

1. A aplicação de Si via foliar à cultura da batata, na forma de ácido silícico estabilizado, reduz a severidade da requeima e a incidência de canela-preta, e aumenta a produtividade e o teor de matéria seca dos tubérculos.

2. O fornecimento de $\mathrm{Si}$ via foliar aumenta a produtividade de tubérculos na cultura da batata, independentemente de seus efeitos sobre a incidência de doenças.

\section{Agradecimentos}

Ao Conselho Nacional de Desenvolvimento Científico e Tecnológico, pela concessão de bolsas; ao Grupo Ioshida, pela concessão da área para condução do experimento 2 .

\section{Referências}

ABDALLA, M.M. Beneficial effects of diatomite on growth, the biochemical contents and polymorphic DNA in Lupinus albus plants grown under water stress. Agriculture and Biology Journal of North America, v.2, p.207-220, 2011.

AZEVEDO, L.A.S. de. Manual de quantificação de doenças de plantas. São Paulo: Grupo Quatro Digital Media, 1998. 114p.
BUCK, G.B.; KORNDÖRFER, G.H.; NOLLA, A.; COELHO, L. Potassium silicate as foliar spray and rice blast control. Journal of Plant Nutrition, v.31, p.231-237, 2008.

CALOMME, M.; COS, P.; D'HAESE, P.; VINGERHOETS, R.; LAMBERTS, L.; DE BROE, M.; VAN HOOREBEKE, C.; BERGHE, D.V. Silicon absorption from stabilized orthosilicic acid and other supplements in healthy subjects. In: ROUSSEL, A.M.; ANDERSON, R.A.; FAVRIER, A.E. (Ed.). Trace elements in man and animals. New York: Plenum, 2000. v.10, p.1111-1114.

CARRÉ-MISSIO, V.; RODRIGUES, F.Á.; SCHURT, D.A.; REZENDE, D.C.; MOREIRA, W.R.; KORNDÖRFER, G.H.; ZAMBOLIM, L. Componentes epidemiológicos da ferrugem do cafeeiro afetados pela aplicação foliar de silicato de potássio. Tropical Plant Pathology, v.37, p.50-56, 2012.

CARRÉ-MISSIO, V.; RODRIGUES, F.Á.; SCHURT, D.A.; REZENDE, D.C.; RIBEIRO, N.B.; ZAMBOLIM, L. Aplicação foliar de silicato de potássio, acibenzolar-S-metil e fungicidas na redução da mancha de Pestalotia em morango. Tropical Plant Pathology, v.35, p.182-185, 2010.

CRUSCIOL, C.A.C.; PULZ, A.L.; LEMOS, L.B.; SORATTO, R.P.; LIMA, G.P.P. Effects of silicon and drought stress on tuber yield and leaf biochemical characteristics in potato. Crop Science, v.49, p.949-954, 2009.

DUARTE, H. da S.S.; ZAMBOLIM, L.; RODRIGUES, F.Á.; RIOS, J.A. Efeito do silicato de potássio isoladamente ou em mistura com fungicida no controle da requeima da batateira. Summa Phytopathologica, v.34, p.68-70, 2008.

ELAWAD, S.H.; GREEN JUNIOR, V.E. Silicon and the rice plant environment: a review of recent research. Il Riso, v.28, p.235-253, 1979.

EPSTEIN, E.; BLOOM, A.J. Nutrição mineral de plantas: princípios e perspectivas. 2.ed. Londrina: Planta, 2006. 403p.

FERNANDES, A.M.; SORATTO, R.P.; EVANGELISTA, R.M.; NARDIN, I. Qualidade físico-química e de fritura de tubérculos de cultivares de batata na safra de inverno. Horticultura Brasileira, v.28, p.299-304, 2010a.

FERNANDES, A.M.; SORATTO, R.P.; SILVA, B.L.; SOUZA-SCHLICK, G.D. de. Crescimento, acúmulo e distribuição de matéria seca em cultivares de batata na safra de inverno. Pesquisa Agropecuária Brasileira, v.45, p.826-835, $2010 \mathrm{~b}$.

GONÇALVES, M.V. Arquitetura de planta, teores de clorofila e produtividade de batata, cv. Atlantic, sob doses de silicato de potássio via foliar. 2009. 51p. Dissertação (Mestrado) Universidade Federal de Uberlândia, Uberlândia.

GONG, H.J.; CHEN, K.M. The regulatory role of silicon on water relations, photosynthetic gas exchange, and carboxylation activities of wheat leaves in field drought conditions. Acta Physiologiae Plantarum, v.33, p.1-6, 2012.

GONG, H.J.; ZHU, X.Y.; CHEN, K.M.; WANG, S.M.; ZHANG, C.G. Silicon alleviates oxidative damage of wheat plants in pots under drought. Plant Science, v.169, p.313-321, 2005.

GUÉVEL, M.-H.; MENZIES, J.G.; BÉLANGER, R.R. Effect of root and foliar applications of soluble silicon on powdery mildew control and growth of wheat plants. European Journal of Plant Pathology, v.119, p.429-436, 2007. 
GUNES, A.; PILBEAM, D.J.; INAL, A.; BAGCI, E.G.; COBAN, $\mathrm{S}$. Influence of silicon on antioxidant mechanisms and lipid peroxidation in chickpea (Cicer arietinum L.) cultivars under drought stress. Journal of Plant Interactions, v.2, p.105-113, 2007.

GUNES, A.; PILBEAM, D.J.; INAL, A.; COBAN, S. Influence of silicon on sunflower cultivars under drought stress. I: Growth, antioxidant mechanisms, and lipid peroxidation. Communications in Soil Science and Plant Analysis, v.39, p.1885-1903, 2008.

HATTORI, T.; INANAGA, S.; ARAKI, H.; PING, A.; MORITA, S.; LUXOVA, M.; LUX, A. Application of silicon enhanced drought tolerance in Sorghum bicolor. Physiologia Plantarum, v.123, p.459-466, 2005.

LANA, R.M.Q.; KORNDÖRFER, G.H.; ZANÃO JÚNIOR, L.A.; SILVA, A.F. da; LANA, A.M.Q. Efeito do silicato de cálcio sobre a produtividade e acumulação de silício no tomateiro. Bioscience Journal, v.19, p.15-20, 2003.

LIANG, Y.C.; SUN, W.C.; SI, J.; RÖMHELD, V. Effects of foliar and root applied silicon on the enhancement of induced resistance to powdery mildew in Cucumis sativus. Plant Pathology, v.54, p.678-685, 2005.

MA, J.F.; MIYAKE, Y.; TAKAHASHI, E. Silicon as a beneficial element for crop plants. In: DATNOFF, L.E.; SNYDER, G.H.; KORNDÖRFER, G.H. (Ed.). Silicon in agriculture. Amsterdam: Elsevier, 2001. p.17-39.

MALAVOLTA, E. Elementos de nutrição de plantas. São Paulo: Agronômica Ceres, 2006. 638p.
PULZ, A.L.; CRUSCIOL, C.A.C.; LEMOS, L.B.; SORATTO, R.P. Influência de silicato e calcário na nutrição, produtividade e qualidade da batata sob deficiência hídrica. Revista Brasileira de Ciência do Solo, v.32, p.1651-1659, 2008.

REIS, T.H.P.; FIGUEIREDO, F.C.; GUIMARÃES, P.T.G.; BOTREL, P.P.; RODRIGUES, C.R. Efeito da associação silício líquido solúvel com fungicida no controle fitossanitário do cafeeiro. Coffee Science, v.3, p.78-80, 2008.

RODRIGUES, C.R.; RODRIGUES, T.M.; LUZ, J.M.Q.; JULIATTI, F.C.; FIGUEIREDO, F.C. Aplicação de silício líquido solúvel via foliar em batata: aumento de 5 toneladas/ha de batata extra. Revista Campo e Negócio, v.26, p.8-10, 2007.

RODRIGUES, F.A.; DATNOFF, L.E. Silicon and rice disease management. Fitopatologia Brasileira, v.30, p.457-469, 2005.

RODRIGUES, F.A.; MCNALLY, D.J.; DATNOFF, L.E.; JONES, J.B.; LABBÉ, C.; BENHAMOU, N.; MENZIES, J.G.; BÉLANGER, R.R. Silicon enhances the accumulation of diterpenoid phytoalexins in rice: a potential mechanism for blast resistance. Phytopathology, v.94, p.177-183, 2004.

SOUSA, J.V. de; RODRIGUES, C.R.; LUZ, J.M.Q.; SOUSA, V.B.F.; CARVALHO, P.C. de; RODRIGUES, T.M.; BRITO, C.H. de. Silicato de potássio via foliar no milho: fotossíntese, crescimento e produtividade. Bioscience Journal, v.26, p.502-513, 2010.

WANG, S.Y.; GALLETA, G.J. Foliar application of potassium silicate induces metabolic changes in strawberry plants. Journal of Plant Nutrition, v.21, p.157-167, 1998.

Recebido em 31 de janeiro de 2012 e aprovado em 4 de junho de 2012

Pesq. agropec. bras., Brasília, v.47, n.7, p.1000-1006, jul. 2012 